\title{
Phosphorus poisoning of molybdenum sulfide hydrodesulfurization catalysts supported on carbon and alumina
}

Citation for published version (APA):

Bouwens, S. M. A. M., Vissers, J. P. R., Beer, de, V. H. J., \& Prins, R. (1988). Phosphorus poisoning of molybdenum sulfide hydrodesulfurization catalysts supported on carbon and alumina. Journal of Catalysis, 112(2), 401-410. https://doi.org/10.1016/0021-9517\%2888\%2990154-6, https://doi.org/10.1016/00219517(88)90154-6

DOI:

10.1016/0021-9517\%2888\%2990154-6

10.1016/0021-9517(88)90154-6

Document status and date:

Published: 01/01/1988

Document Version:

Publisher's PDF, also known as Version of Record (includes final page, issue and volume numbers)

Please check the document version of this publication:

- A submitted manuscript is the version of the article upon submission and before peer-review. There can be important differences between the submitted version and the official published version of record. People interested in the research are advised to contact the author for the final version of the publication, or visit the $\mathrm{DOI}$ to the publisher's website.

- The final author version and the galley proof are versions of the publication after peer review.

- The final published version features the final layout of the paper including the volume, issue and page numbers.

Link to publication

\footnotetext{
General rights

- You may freely distribute the URL identifying the publication in the public portal. follow below link for the End User Agreement:

www.tue.nl/taverne

Take down policy

If you believe that this document breaches copyright please contact us at:

openaccess@tue.nl

providing details and we will investigate your claim.
}

Copyright and moral rights for the publications made accessible in the public portal are retained by the authors and/or other copyright owners and it is a condition of accessing publications that users recognise and abide by the legal requirements associated with these rights.

- Users may download and print one copy of any publication from the public portal for the purpose of private study or research.

- You may not further distribute the material or use it for any profit-making activity or commercial gain

If the publication is distributed under the terms of Article 25fa of the Dutch Copyright Act, indicated by the "Taverne" license above, please 


\title{
Phosphorus Poisoning of Molybdenum Sulfide Hydrodesulfurization Catalysts Supported on Carbon and Alumina
}

\author{
Stephan M. A. M. Bouwens, Jan P. R. Vissers, ${ }^{1}$ Vincent H. J. De Beer, \\ AND RoEl PRINS \\ Laboratory for Inorganic Chemistry and Catalysis, Eindhoven University of Technology, P.O. Box 513, \\ $5600 \mathrm{MB}$ Eindhoven, The Netherlands
}

Received November 7, 1986; revised December 21, 1987

\begin{abstract}
Phosphorus-containing Mo sulfide catalysts supported on $\gamma-\mathrm{Al}_{2} \mathrm{O}_{3}$ and activated carbon were evaluated for their thiophene HDS activities. Phosphorus was added as phosphoric acid to the carrier material prior to the molybdenum component. The thiophene HDS activity of the carbonsupported catalysts was strongly decreased by phosphorus, while alumina-supported catalysts were not poisoned by phosphorus when present at moderate contents. The structural characteristics and degree of dispersion of the sulfided carbon-supported catalysts were determined by X-ray photoelectron spectroscopy and dynamic $\mathrm{CO}$ chemisorption. The cause of the phosphorus poisoning could not be related to a decrease in active phase dispersion or to incomplete sulfidation of the oxidic precursor catalyst. $\mathrm{CO}$ chemisorption revealed that in a phosphorus-containing catalyst anion vacancies were blocked. It was suggested that phosphorus poisoning can be related to phosphine $\left(\mathrm{PH}_{3}\right)$, created by reduction of phosphate, probably during the presulfiding treatment. The poisoning effect can be explained as resulting from the adsorption of phosphine on the anion vacancies. The fact that alumina-supported catalysts are not poisoned by phosphorus can be explained by the strong interaction of phosphate with the alumina support. Due to this strong interaction, phosphate will not be reduced to phosphine under the sulfiding and reaction conditions applied. 1988 Academic Press, Inc.
\end{abstract}

\section{INTRODUCTION}

Alumina-supported molybdenum oxide or molybdenum sulfide catalysts and promoted $\mathrm{Co}-\mathrm{Mo} / \mathrm{Al}_{2} \mathrm{O}_{3}$ and $\mathrm{Ni}-\mathrm{Mo} / \mathrm{Al}_{2} \mathrm{O}_{3}$ systems have been widely investigated with respect to their ability to catalyze hydrotreating reactions such as HDS and HDN. Efforts have also been made to improve their catalytic activity by finding appropriate secondary promoters.

Phosphorus, present as phosphate, can be considered to be one of the most effective modifiers to the above-mentioned catalysts; in fact, it appears to be a component in a number of commercial catalysts. In the literature, phosphate is described as a promoter for hydrodesulfurization (1-9), hy-

\footnotetext{
${ }^{1}$ Present address: Esso Benelux, Antwerp Refinery, Polderdijkweg, 2030 Antwerp, Belgium.
}

drodenitrogenation (2-4), and hydrodemetallization (5) reactions.

In addition to promoting the catalytic activity, other beneficial properties have been ascribed to the phosphate additive. It has been said to provide increasing strength and heat stability to the alumina support $(10,11)$. Usually, phosphoric acid is added to increase the solubility of the precursor metal salts in the impregnation solutions, the advantage being that promoted catalysts can be prepared with a single impregnation step $(1-3,6-9,12,13)$. The promotion effect of phosphorus on the catalytic activity is tentatively explained as resulting from an improved dispersion of the precursor metal salts on the support. More specifically, because of the high solubility of the metal salts in the phosphoric acid-containing impregnation solution, the deposition of large crystalline aggregates on the support 
surface is minimized $(1-3,6-9)$. Nevertheless, the promotion effect of phosphorus on HDS activity is not really understood, and the structures of phosphorus-containing catalysts have not been fully elucidated.

It is also known (2) that large amounts of phosphoric acid (larger than $12 \mathrm{wt} \%$ ) adversely affect the activity of the catalyst for both HDS and HDN reactions. This poisoning effect of phosphorus is likewise not understood.

In striking contrast to alumina-supported catalysts, it was demonstrated that for carbon-supported molybdenum sulfide catalysts, phosphorus should be regarded as a severe poison, as it drastically reduces the HDS activity of the catalysts even at very low phosphorus contents (14-16). This contradictory behavior of phosphorus, being a promoter on the one hand and a poison on the other, is very intriguing.

The present study aims to shed more light on this problem by evaluating the properties of phosphate-containing activated carbon- and alumina-supported Mo catalysts. A series of Mo catalysts with varying phosphorus content and nearly constant metal content was prepared and evaluated for their thiophene HDS activity. $\mathrm{X}$-ray photoelectron spectroscopy and dynamic $\mathrm{CO}$ chemisorption were used to characterize the catalysts.

\section{EXPERIMENTAL}

\section{Catalyst Preparation}

A. Alumina-supported catalysts. Phosphorus-containing catalysts, supported on alumina (Ketjen Grade B; BET surface area, $270 \mathrm{~m}^{2} \mathrm{~g}^{-1}$; pore volume, $1.9 \mathrm{~cm}^{3} \mathrm{~g}^{-1}$ ), were prepared by a stepwise pore volume impregnation method in which aqueous phosphoric acid (Merck p.a.) was added first, followed by the active metal salt component, ammonium heptamolybdate (Merck p.a.). After the impregnation step, the catalysts were dried in air (16 h), starting at $293 \mathrm{~K}$ and gradually increasing the temperature to $383 \mathrm{~K}(3 \mathrm{~h})$ where they were kept overnight. Finally, the catalysts were subjected to a calcination treatment at $823 \mathrm{~K}$ for $2 \mathrm{~h}$ in air. A series of catalysts was prepared, containing a nearly constant amount of Mo and varying amounts of phosphate.

B. Carbon-supported catalysts. The support used was an activated carbon (Norit RX3-Extra; BET surface area, $1190 \mathrm{~m}^{2} \mathrm{~g}^{-1}$; pore volume, $1.0 \mathrm{~cm}^{3} \mathrm{~g}^{-1}$ ). Three different procedures have been applied for introducing phosphorus into the catalysts.

1. The carbon support was immersed in an aqueous solution of $\mathrm{H}_{3} \mathrm{PO}_{4}$. After refiuxing for $1 \mathrm{~h}$, when most of the phosphate was chemisorbed by the carbon, the samples were filtered off and dried overnight in air at $383 \mathrm{~K}$. Catalysts were prepared on the phosphate-containing carbon supports by pore volume impregnation using aqueous solutions of ammonium heptamolybdate. A series of catalysts containing a constant amount of Mo as an active metal component, and having varying amounts of phosphate was prepared. After impregnation, the catalysts were dried in air, starting at $293 \mathrm{~K}$ and increasing the temperature to 383 $\mathrm{K}$ over $3 \mathrm{~h}$, where they were kept overnight. The carbon-supported samples were not subjected to a calcination step because this is detrimental to the dispersion of the active phase.

2. The carbon support was impregnated (pore volume impregnation) with an aqueous solution of molybdophosphate $\left(\mathrm{H}_{3} \mathrm{P}\right.$ $\left(\mathrm{Mo}_{3} \mathrm{O}_{10}\right)_{4} \cdot \mathrm{H}_{2} \mathrm{O}$, Janssen Pharmaceutica). This complex will in the following be denoted 12-MPA. One catalyst sample was prepared by pore volume impregnation with 12-MPA on a carbon support which already contained some phosphate (which was introduced according to procedure 1). The catalysts were dried overnight at $383 \mathrm{~K}$ in air.

3. After sulfidation of the phosphorusfree Mo catalyst, prepared by pore volume impregnation in a fashion similar to that described before (procedure 1), an aqueous 
solution of phosphoric acid was added to the sulfided catalysts by pore volume impregnation in a nitrogen atmosphere. This catalyst was dried overnight under flowing nitrogen at $293 \mathrm{~K}$. It should be noted that the catalytic structure does not change significantly as a result of this impregnation procedure. We checked this by impregnating a sulfided Mo catalyst with pure water and measuring its thiophene HDS activity. The HDS activity turned out to be nearly the same as those of the parent Mo catalyst, indicating that no significant change in catalyst structure occurred.

The metal and phosphate contents of the precursor catalyst were determined by means of atomic absorption spectroscopy (Perkin-Elmer 3030 AAS spectrometer) and a standard analysis procedure (17), respectively.

C. Catalyst notation. In this article, catalysts will be denoted as $\operatorname{Me}(x) /(Y+\mathrm{P}(z))$, in which $x$ represents the weight percentage of Mo, and $z$ the weight percentage of phosphate. $Y$ denotes the type of carrier, Al for alumina and $\mathrm{C}$ for carbon (preparation procedures 1 and 2). The carbon-supported catalyst prepared by procedure 3 will be denoted $\left(\mathrm{MoS}_{2} / \mathrm{C}\right)+\mathrm{P}$. In Table 1 , the different catalysts are shown schematically.

\section{Catalyst Activity}

Catalytic activity for thiophene HDS was tested in a micro-flow-reactor operating at $673 \mathrm{~K}$ and atmospheric pressure. Catalyst samples $(0.2 \mathrm{~g})$ were sulfided in situ in a mixture of $\mathrm{H}_{2} \mathrm{~S} / \mathrm{H}_{2}\left(10 \mathrm{vol} \% \mathrm{H}_{2} \mathrm{~S}\right.$, flow rate $\left.60 \mathrm{~cm}^{3} \mathrm{~min}^{-1}\right)$. The following temperature program was applied: starting at $293 \mathrm{~K}$, the temperature was linearly increased at a rate of $6 \mathrm{~K} \mathrm{~min}-1$ until $673 \mathrm{~K}$, followed by extended sulfidation at $673 \mathrm{~K}$ for $2 \mathrm{~h}$. In the case of catalysts prepared according to procedure 3 (see section on catalyst preparation), the extended sulfidation at $673 \mathrm{~K}$ was carried out for only $0.5 \mathrm{~h}$. At $673 \mathrm{~K}$ a mixture of thiophene and $\mathrm{H}_{2}(6.2$ vol\% thiophene) was introduced, at a flow rate of 50

\section{TABLE 1}

Schematic Representation of the Catalysts

\begin{tabular}{lcl}
\hline $\begin{array}{l}\text { Support } \\
\text { material }\end{array}$ & $\begin{array}{c}\text { Preparation } \\
\text { procedure }^{a}\end{array}$ & \multicolumn{1}{c}{$\begin{array}{c}\text { Catalyst } \\
\text { notation }\end{array}$} \\
\hline $\begin{array}{l}\text { Alumina } \\
\text { Carbon }\end{array}$ & - & $\mathrm{Mo} /(\mathrm{Al}+\mathrm{P})$ \\
& 1 & $\mathrm{Mo} /(\mathrm{C}+\mathrm{P})$ \\
& 2 & $12-\mathrm{MPA} / \mathrm{C}^{b}$ \\
& 3 & $12-\mathrm{MPA}_{(\mathrm{C}+\mathrm{P})}$ \\
& & $\left.\mathrm{MoS}_{2} / \mathrm{C}\right)+\mathrm{P}$ \\
\hline
\end{tabular}

"For carbon as support material, three different preparation procedures, described in the section on catalyst preparation, have been applied. For alumina as support material, the conventional pore volume impregnation procedure has been used.

${ }^{b}$ 12-MPA stands for the $\mathrm{H}_{3} \mathrm{P}\left(\mathrm{Mo}_{3} \mathrm{O}_{10}\right)_{4}$ complex.

$\mathrm{cm}^{3} \min ^{-1}$. The reaction products were analyzed by on-line chromatography. The thiophene conversion measured after a $2-h$ run was taken to calculate the first-order rate constants for HDS and the consecutive butene hydrogenation (HYD) reaction (18). The HDS reaction rate constant $\left(k_{\mathrm{HDS}}\right)$ is calculated as

$$
k_{\mathrm{HDS}}=-F / W * \ln (1-x),
$$

in which $F$ is the total flow rate (in $\mathrm{m}^{3} \mathrm{~s}^{-1}$ ), $W$ the weight of catalyst (in $\mathrm{kg}$ ), and $x$ the thiophene conversion (in \%).

The intrinsic catalytic activity is expressed as a quasi-turnover frequency (QTOF: moles thiophene converted, per mole active metal, per second).

\section{$X$-Ray Photoelectron Spectroscopy (XPS)}

XP spectra of the oxidic samples were recorded on a Physical Elcctronics 550 XPS/AES spectrometer equipped with a $\mathrm{Mg}$ anode (1253.6 eV) and a double-pass cylindrical mirror analyzer operating at a pass energy of $50 \mathrm{eV}$. The powdered samples were pressed on double-sided adhesive tape. Spectra were recorded in steps of 0.2 $\mathrm{eV}$. The pressure did not exceed $6.6 \times 10^{-6}$ $\mathrm{Pa}$ and the temperature was approximately $293 \mathrm{~K}$.

XP spectra of the sulfided samples were recorded on an AEI ES 200 spectrometer 
equipped with an $\mathrm{Al}$ anode (1486.6 eV) and a spherical analyzer operating at a pass energy of $60 \mathrm{eV}$. In order to avoid contact of the sulfided catalysts with air, a special sulfiding reactor was used (19) which allowed transfer of the samples to a $\mathrm{N}_{2}$-flushed glovebox attached to the XPS apparatus without exposure to air. After sulfidation according to the procedure described above, the catalyst samples were flushed with purified $\mathrm{He}$ for $15 \mathrm{~min}$ at $673 \mathrm{~K}$ and subsequently cooled to room temperature. The samples were mounted on the specimen holder by means of double-sided adhesive tape. Spectra were recorded at $293 \mathrm{~K}$ in steps of $0.2 \mathrm{eV}$, and the pressure was lower than $1.3 \times 10^{-6} \mathrm{~Pa}$.

The $\mathrm{C} 1 s$ peak $(284.6 \mathrm{eV})$ was used as an internal standard for binding energy calibration and the Mo over $\mathrm{C}$ photoelectron intensity ratios were used to measure the degree of dispersion of the Mo phase on the support.

Theoretical intensity ratios were calculated according to the catalyst model described by Kerkhof and Moulijn (20), assuming that the Mo phase is exclusively present as isolated or polymerized monolayer species. Electron mean free paths were calculated according to Penn (21), and electron cross sections according to Scofield (22).

\section{Dynamic CO Chemisorption}

Dynamic CO chemisorption was measured after sulfidation of the oxidic catalysts in a thiophene $/ \mathrm{H}_{2}(7.9 \mathrm{vol} \%$ thio- phene) reaction mixture at $693 \mathrm{~K}$. At the end of a $24-h$ period needed for stabilization, the sulfided catalyst was subsequently flushed with Ar for $2 \mathrm{~h}$ at $693 \mathrm{~K}$ and then measured for its carbon monoxide chemisorption capacity in the reactor itself by a dynamic method. Successive pulses are run onto the sulfided catalyst held at $273 \mathrm{~K}$ until cumulative adsorption remains constant. For more detailed information, reference may be made to the paper of Bachelier et al. (23).

\section{RESULTS}

\section{Thiophene HDS Activity}

A. Alumina-supported catalysts. In Table 2 the catalytic activities for $\mathrm{Mo} /(\mathrm{Al}+\mathrm{P})$ are shown. The $k_{\mathrm{HDS}}$ values included in this table show that the promoter effect of phosphate is ncgligible. More importantly, however, these data clearly show that, under the conditions used, phosphate does not act as a poison. The butene hydrogenation activity $k_{\mathrm{HYD}}$ (expressed relative to HDS activity, $k_{\mathrm{HDS}}$ ) is also not significantly changed by phosphate.

B. Carbon-supported catalysts. The catalyst compositions and thiophene HDS activities of the carbon-supported Mo catalysts are shown in Table 3 . It should be noted that $0.03 \mathrm{wt} \% \mathrm{PO}_{4}^{3-}$ was present on the pure carbon support, in spite of the fact that it had been industrially purified with an $\mathrm{HCl}$ washing. In Fig. 1 the quasi-turnover frequencies (QTOF) are plotted for all the samples mentioned in Table 3. Clearly, the

TABLE 2

Activities on Alumina-Supported Sulfided Mo Catalysts

\begin{tabular}{cccccccc}
\hline \multirow{2}{*}{$\begin{array}{c}\text { Type of } \\
\text { catalyst }\end{array}$} & \multicolumn{2}{c}{ Catalyst composition } & & \multicolumn{3}{c}{ Catalytic activity } \\
\cline { 2 - 5 } & $\begin{array}{c}\mathrm{wt} \% \\
\mathrm{Mo}\end{array}$ & $\begin{array}{c}\mathrm{wt} \% \\
\mathrm{PO}_{4}^{3-}\end{array}$ & $\frac{\mathrm{PO}_{4}^{3-}}{\mathrm{Mo}}$ & & $\begin{array}{c}\text { Conv. } \\
(\%)\end{array}$ & $\begin{array}{c}k_{\mathrm{HDS}} \times 10^{3} \\
\left(\mathrm{~m}^{3} \mathrm{~kg}^{-1} \mathrm{~s}^{-1}\right)\end{array}$ & $\frac{k_{\mathrm{HYD}}}{k_{\mathrm{HDS}}}$ \\
\hline $\mathrm{Mo} /(\mathrm{Al}+\mathrm{P})$ & 7.1 & 0 & 0 & 6.9 & 0.68 & 3.2 \\
& 7.0 & 1.4 & 0.20 & & 7.6 & 0.76 & 3.2 \\
& 7.0 & 1.8 & 0.26 & & 7.2 & 0.72 & 3.0 \\
\hline
\end{tabular}


TABLE 3

Activities on Carbon-Supported Sulfided Mo Catalysts

\begin{tabular}{|c|c|c|c|c|c|c|c|}
\hline \multirow{2}{*}{$\begin{array}{l}\text { Type of } \\
\text { catalyst }^{a}\end{array}$} & \multicolumn{3}{|c|}{ Catalyst composition } & \multicolumn{4}{|c|}{ Catalytic activity } \\
\hline & $\begin{array}{l}\text { wt } \% \\
\text { Mo }\end{array}$ & $\begin{array}{l}\mathrm{wt} \% \\
\mathrm{PO}_{4}^{3-}\end{array}$ & $\frac{\mathrm{PO}_{4}^{3-}}{\mathrm{Mo}}$ & $\begin{array}{l}\text { Conv. } \\
(\%)\end{array}$ & $\begin{array}{c}k_{\mathrm{HDS}} \times 10^{3} \\
\left(\mathrm{~m}^{3} \mathrm{~kg}^{-1} \mathrm{~s}^{-1}\right)\end{array}$ & $\begin{array}{c}\text { QTOF } \times 10^{3} \\
\text { (mol thiophene/ } \\
\text { mol Mo } \cdot \mathrm{s} \text { ) }\end{array}$ & $\frac{k_{\mathrm{HYD}}}{k_{\mathrm{HOS}}}$ \\
\hline \multirow[t]{6}{*}{$\mathrm{Mo} /(\mathrm{C}+\mathrm{P})$} & 7.0 & 0.03 & 0.004 & 24.0 & 2.6 & 4.1 & 2.4 \\
\hline & 7.4 & 0.07 & 0.01 & 22.7 & 2.5 & 3.6 & 2.8 \\
\hline & 7.4 & 0.14 & 0.02 & 19.2 & 2.0 & 2.9 & 2.6 \\
\hline & 7.6 & 0.28 & 0.04 & 17.0 & 2.0 & 2.8 & 2.9 \\
\hline & 7.5 & 0.40 & 0.05 & 14.3 & 1.5 & 2.2 & 3.3 \\
\hline & 7.2 & 2.60 & 0.37 & 4.0 & 0.4 & 0.6 & 5.8 \\
\hline 12-MPA/C & 8.6 & 0.71 & 0.08 & 12.0 & 1.2 & 1.5 & 2.9 \\
\hline 12-MPA/(C $+\mathrm{P})$ & 7.3 & 1.34 & 1.19 & 2.6 & 0.6 & 0.9 & 5.3 \\
\hline$\left(\mathrm{MoS}_{2} / \mathrm{C}\right)+\mathrm{P}$ & 6.3 & 2.60 & 0.42 & 2.4 & 0.2 & 0.3 & 7.6 \\
\hline
\end{tabular}

${ }^{a}$ For catalyst notation, see Experimental section.

QTOF values of $\mathrm{Mo} /(\mathrm{C}+\mathrm{P})$ catalysts (procedure 1) decrease rapidly with only small amounts of phosphate, an observation already made in previous publications (1416). The butene hydrogenation activity $k_{\mathrm{HYD}}$ (expressed in $k_{\mathrm{HYD}} / k_{\mathrm{HDS}}$ ) seems less affected by phosphate than $k_{\mathrm{HDS}}$ : the ratio $k_{\mathrm{HYD}} / k_{\mathrm{HDS}}$ increases at high phosphate loadings. Thus, hydrogenation is still relatively fast, whereas hydrodesulfurization is strongly decreased. The HDS activity of catalysts prepared by impregnation with an aqueous solution of the 12-MPA complex (procedure 2) is in line with the ordinary

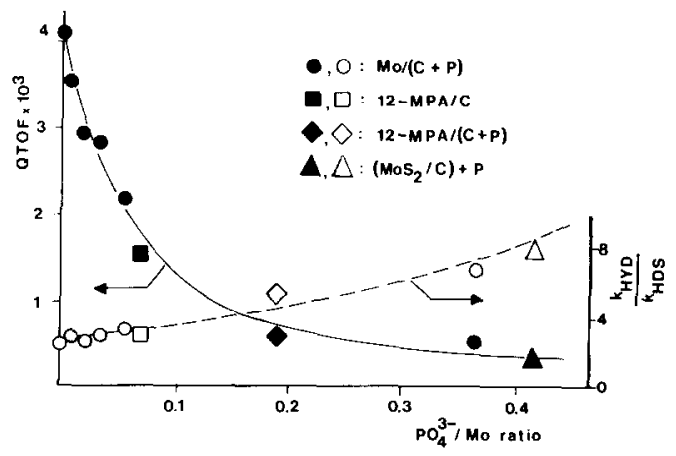

FIG. 1. QTOF values and $k_{\mathrm{HYD}} / k_{\mathrm{HDS}}$ ratios of sulfided $\mathrm{Mo} /(\mathrm{C}+\mathrm{P})$ catalysts as a function of the $\mathrm{PO}_{4}^{3-} / \mathrm{Mo}$ ratio in the oxidic precursor state.
$\mathrm{Mo} /(\mathrm{C}+\mathrm{P})$ catalysts as can be seen in Fig. 1. Interestingly, introduction of phosphorus into a sulfided $\mathrm{Mo} / \mathrm{C}$ catalyst (procedure 3 ) also resulted in a strong poisoning effect.

\section{Characterization of Carbon-Supported Catalysts}

XPS measurements were carried out on the $\mathrm{Mo}(7.2) /(\mathrm{C}+\mathrm{P}(2.60))$ and the $\mathrm{Mo}(7.0) /$ $\mathrm{C}$ catalyst, as well as on the pure 12-MPA complex, in both the oxidic and the sulfided form. The results are collected in Table 4. The XPS results seem to indicate that the Mo particle size of the phosphorus-containing precursor catalyst $(1.7 \mathrm{~nm})$ is larger than that of the P-free $\mathrm{Mo} / \mathrm{C}$ sample $(<1.0$ $\mathrm{nm})$. This could mean that in the oxidic state a molybdophosphate phase with a larger particle size than that of the molybdate phase is formed. Upon sulfidation, however, all the Mo particles are converted into $\mathrm{MoS}_{2}$ as judged from the Mo $3 d$ binding energies (229.3 and $232.5 \mathrm{eV} \pm 0.2 \mathrm{eV}$ ) and the sulfur-to-molybdenum ratio of $2.2 \pm$ 0.2 . The binding energies of the Mo $3 d$ and $\mathrm{S} 2 p$ XPS electrons in sulfided $\mathrm{Mo} /(\mathrm{C}+\mathrm{P})$ are almost equal to those of the sulfided $\mathrm{Mo} / \mathrm{C}$ catalyst, indicating that phosphorus does not influence the chemical state of $\mathrm{MoS}_{2}$. 
TABLE 4

XPS Results of P-Free Mo/C, P-Containing Mo/C, and $\mathrm{H}_{3} \mathrm{P}\left(\mathrm{Mo}_{3} \mathrm{O}_{10}\right)_{4}$

\begin{tabular}{|c|c|c|c|c|c|c|}
\hline \multirow[b]{2}{*}{ Oxidic state } & \multicolumn{2}{|c|}{$\operatorname{Mo}(7.0) / C$} & \multicolumn{2}{|c|}{$\mathrm{Mo}(7.2) /(\mathrm{C}+\mathrm{P}(2.60))$} & \multicolumn{2}{|c|}{ 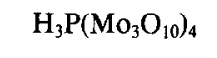 } \\
\hline & & & & & & \\
\hline Mo $3 d_{5 / 2,3 / 2}$ B.E. (eV) & 232.4 & 235.4 & 232.6 & 236.0 & 232.4 & 235.4 \\
\hline$I_{\mathrm{Mo}} / I_{\mathrm{C}}$ & \multirow{2}{*}{\multicolumn{2}{|c|}{0.074}} & \multicolumn{2}{|c|}{0.063} & \multirow{3}{*}{\multicolumn{2}{|c|}{133.8}} \\
\hline P $2 p$ B.E. $(\mathrm{eV})$ & & & & & & \\
\hline Particle size $(\mathrm{nm})$ & \multicolumn{2}{|c|}{$<1.0$} & \multicolumn{2}{|c|}{1.7} & & \\
\hline \multicolumn{7}{|l|}{ Sulfided state } \\
\hline Mo $3 d_{5 / 2,3 / 2}$ B.E. (eV) & 229.3 & 232.4 & 229.3 & 232.5 & 229.4 & 232.6 \\
\hline$I_{\mathrm{Mo}} / I_{\mathrm{C}}$ & \multicolumn{2}{|c|}{0.061} & \multicolumn{2}{|c|}{0.058} & & \\
\hline S/Mo atomic ratio ${ }^{a}$ & & & \multirow{2}{*}{\multicolumn{2}{|c|}{$\begin{array}{r}2.2 \\
162.7\end{array}$}} & \multicolumn{2}{|c|}{1.5} \\
\hline S $2 p$ B.E. $(\mathrm{eV})$ & \multirow{2}{*}{\multicolumn{2}{|c|}{162.8}} & & & \multicolumn{2}{|c|}{162.5} \\
\hline P $2 p$ B.E. $(\mathrm{eV})$ & & & \multirow{2}{*}{\multicolumn{2}{|c|}{$\begin{array}{r}133.8 \\
2.6\end{array}$}} & \multirow{2}{*}{\multicolumn{2}{|c|}{134.1}} \\
\hline Particle size $(\mathrm{nm})$ & \multicolumn{2}{|c|}{2.2} & & & & \\
\hline
\end{tabular}

${ }^{a}$ The S/Mo atomic ratio was calculated after subtraction of the amount of sulfur formed due to sulfidation of the carbon support itself $\left(I_{S} / I_{C}=0.003\right)$.

The size of the $\mathrm{MoS}_{2}$ particles present in the sulfided $\mathrm{Mo}(7.2) /(\mathrm{C}+\mathrm{P}(2.60))$ catalyst $(2.6 \mathrm{~nm})$ is consistent with that of $\operatorname{Mo}(7.0) /$ C: $2.2 \mathrm{~nm}$. This signifies that in a sulfided $\mathrm{Mo} /(\mathrm{C}+\mathrm{P})$ catalyst the active phase dispersion is roughly the same as that for a sulfided phosphorus-free $\mathrm{Mo} / \mathrm{C}$ catalyst. The $\mathrm{P} 2 p$ binding energy in the sulfided state of $\mathrm{Mo}(7.2) /(\mathrm{C}+\mathrm{P}(2.60))$ is the same as that of its oxidic precursor: $133.8 \pm 0.2$ $\mathrm{eV}$.

To see if a molybdophosphate can be converted into $\mathrm{MoS}_{2}$, the 12-MPA complex was sulfided under the standard conditions and XP spectra of the oxidic and sulfided forms were taken. These XPS data show that 12-MPA is sulfided to form a Mo sulfide (according to the Mo $3 d$ binding energies) with a $\mathrm{S} / \mathrm{Mo}$ ratio of 1.5 . This value is, however, lower, as expected for $\mathrm{MoS}_{2}$, so possibly sulfidation was not complete. The $\mathrm{P} 2 p$ binding energy of the complex in the oxidic state is the same as that of $\mathrm{Mo} /(\mathrm{C}+$ $\mathrm{P}$ ), while in the sulfided state the $\mathrm{P} 2 p$ binding energy is also close to the reported value for the sulfided $\mathrm{Mo} /(\mathrm{C}+\mathrm{P})$ catalyst.

$\mathrm{CO}$ chemisorption measurements were performed on $\mathrm{Mo}(6.9) /(\mathrm{C}+\mathrm{P}(2.30))$ and on the P-free $\mathrm{Mo}(7.0) / \mathrm{C}$ catalyst. The molar ratio $\mathrm{CO} / \mathrm{Mo}$ amounted to 0.04 for $\mathrm{Mo}(7.0)$ /
C but only 0.003 for $\mathrm{Mo}(6.9) /(\mathrm{C}+\mathrm{P}(2.30))$. Apparently, the $\mathrm{CO}$ chemisorption is strongly decreased in the presence of phosphorus.

\section{Formation of $\mathrm{PH}_{3}$}

It is known from the literature (24) that $\mathrm{H}_{3} \mathrm{PO}_{4}$ and $\left(\mathrm{NH}_{4}\right)_{2} \mathrm{HPO}_{4}$ can be reduced by $\mathrm{H}_{2}$ to $\mathrm{PH}_{3}$ (phosphine) at $873 \mathrm{~K}$. It has also been reported (25) that a catalyst consisting of $\mathrm{H}_{3} \mathrm{PO}_{4}$ on activated charcoal is reduced by $\mathrm{H}_{2}$, starting at $673 \mathrm{~K}$ and resulting in the formation of white phosphorus. Since these experiments show that phosphate on a carbon support can be reduced, possibly to phosphine, it is instructive to investigate this phenomenon on our catalysts. An cxperiment was carried out in which a phosphate-containing carbon support (27 wt\% $\left.\mathrm{PO}_{4}^{3-}\right)$ was reduced by $\mathrm{H}_{2}$ at $673 \mathrm{~K}(3 \mathrm{~h})$. The outlet gases were bubbled through an aqueous solution of silver nitrate, an indicator for the presence of $\mathrm{PH}_{3}$. It was indeed found that $\mathrm{PH}_{3}$ had been formed. To investigate the possibility of poisoning by phosphine, we sulfided a $\operatorname{Mo}(7.0) / C$ catalyst and after sulfidation (according to the standard procedure) we introduced gaseous $\mathrm{PH}_{3}$ in a helium gas flow into the reactor at $673 \mathrm{~K}$. 
This experiment was carried out in situ and $\mathrm{PH}_{3}$ was prepared by hydrolysis of phosphonium iodide. After the $\mathrm{PH}_{3}$ treatment the thiophene HDS activity was measured. It was discovered that HDS activity had drastically decreased: $k_{\mathrm{HDS}}$ was $0.2 \times 10^{-3}$ $\mathrm{m}^{3} \mathrm{~kg}^{-1} \mathrm{~s}^{-1}$, while $\mathrm{Mo}(7.0) / \mathrm{C}$ generally has a $k_{\mathrm{HDS}}$ of $2.6 \times 10^{-3} \mathrm{~m}^{3} \mathrm{~kg}^{-1} \mathrm{~s}^{-1}$; this means a decrease in HDS activity of more than $90 \%$ !

\section{DISCUSSION}

To explain the poisoning effect of phosphorus in $\mathrm{Mo} /(\mathrm{C}+\mathrm{P})$ catalysts, a number of explanations may be postulated:

(i) formation of a catalytically inactive metal-phosphate complex,

(ii) decrease in active phase dispersion,

(iii) incomplete sulfidation of the metal oxidic particles, and

(iv) poisoning of the active sites.

Concerning the first possibility, the formation of a molybdophosphate complex in the oxidic precursor catalyst is not excluded. This was evidenced from the catalyst prepared from 12-MPA which showed an HDS activity similar to that of the conventional $\mathrm{Mo} /(\mathrm{C}+\mathrm{P})$ catalysts. However, phosphorus addition to a sulfided $\mathrm{Mo} / \mathrm{C}$ catalyst (to prevent the formation of the oxidic molybdophosphate complex) resulted in the same IIDS activity as that of a Mo/(C + P) catalyst. Furthermore, XPS of a sulfided 12-MPA complex showed that this complex can easily be converted to Mo sulfide. These experiments prove that the existence of a molybdophosphate is not at all necessary for the $\mathrm{P}$ poisoning effect. The second possibility is also not valid since XPS showed that the active phase dispersion of $\mathrm{Mo} /(\mathrm{C}+\mathrm{P})$ after sulfidation is not significantly decreased compared to that in $\mathrm{Mo} / \mathrm{C}$.

From the XPS results it appears that a $\mathrm{Mo} /(\mathrm{C}+\mathrm{P})$ catalyst is completely sulfided: the $\mathrm{S} / \mathrm{Mo}$ ratio is 2.2 and the binding energies of the Mo $3 d$ XPS electrons in sulfided $\mathrm{Mo} /(\mathrm{C}+\mathrm{P})$ are almost the same as those in $\mathrm{Mo} / \mathrm{C}$. This means that the explanation of the $P$ poisoning in terms of a reduction in degree of sulfiding (possibility (iii)) is not valid either. From these results it seems that the active molybdenum sulfide phase of $\mathrm{Mo} /(\mathrm{C}+\mathrm{P})$ is structurally equivalent to that of P-free $\mathrm{Mo} / \mathrm{C}$. Yet the $\mathrm{CO}$ chemisorption capacity is strongly decreased in the presence of phosphorus. Bachelier et al. $(23,26,27)$ have shown that a linear correlation exists between CO chemisorption and thiophene HDS activity for unpromoted $\mathrm{Mo} / \mathrm{Al}$. According to Bachelier et al., $\mathrm{CO}$ chemisorption can be regarded as a means for titration of the anion vacancies, whereby one $\mathrm{CO}$ molecule would be able to detect onc vacancy. Decreased CO chemisorption therefore points to a decrease in the number of vacancies.

Concerning the $\operatorname{Mo}(7.0) / \mathrm{C}$ and $\operatorname{Mo}(6.9) /$ $(\mathrm{C}+\mathrm{P}(2.30))$ catalysts, the decrease in $\mathrm{CO}$ chemisorption (90\%) is remarkably proportional to the decrease in thiophene HDS activity $(85 \%)$ measured for a comparable $\mathrm{Mo}(7.2) /(\mathrm{C}+\mathrm{P}(2.60))$ catalyst. $\mathrm{CO}$ chemisorption thus reveals that the number of sulfur anion vacancies decreases when phosphorus is present on the catalyst. Since XPS showed that dispersion does not significantly decrease, this can only mean that the anion vacancies are in some way blocked, possibly by a phosphorus compound. This phosphorus compound could be $\mathrm{PH}_{3}$, which was demonstrated to be a possible poisoning agent. The phosphorus poisoning effect can consequently be explained as resulting from the adsorption of $\mathrm{PH}_{3}$ on the vacancy sites of the metal sulfides, in this way deactivating these sites.

Thus, poisoning of the active sites (possibility (iv)) seems the most likely explanation for all the observed phenomena of the phosphorus poisoning effect. It can explain why catalysts prepared by impregnation with a molybdophosphate complex (procedure 2) are poisoned: the phosphate in the complex is reduced to phosphine while molybdenum is sulfided during the presulfiding treatment. It can also explain why a sulfided catalyst is poisoned by phosphorus (the catalyst prepared according to proce- 
dure 3): phosphate is reduced during the additional presulfiding treatment to phosphine. In this respect it is relevant to note that also during the thiophene HDS run (the feed of which contains $93.8 \mathrm{vol} \% \mathrm{H}_{2}$ ) the reduction of phosphate can occur. On the other hand, it is observed that the initial thiophene HDS activity (measured after a 5-min run time) of the phosphorus-containing catalysts is always lower compared with the phosphorus-free catalysts, showing that a part of the poisoning already occurs during the presulfiding stage.

The XPS results show that the $\mathrm{P} 2 p$ binding energy of the $\mathrm{Mo} /(\mathrm{C}+\mathrm{P})$ catalyst in the sulfided state is the same as that in the oxidic state. This suggests that a large fraction of phosphorus is still present as phosphate. On the other hand, a P $2 p$ binding energy of $133.8 \mathrm{eV}$ points to the presence of phosphorus as $\mathrm{P}^{5+}$ or $\mathrm{P}^{3+}$ and rules out lower valencies (28). Thus, the idea of phosphine is entirely possible.

In regard to the phosphorus poisoning, it is noteworthy that arsenic also poisons hydrodesulfurization catalysts (sulfided $\mathrm{Mo} /$ $\mathrm{Al}$ and $\mathrm{Co}-\mathrm{Mo} / \mathrm{Al}$ ), as found by Merryfield et al. (29). According to these authors, arsenic alters the electronic structure of the active sites, perhaps through the occupation of anion vacancies by arsenic atoms or clusters. The analogy between arsenic and phosphorus poisoning can now be understood, since both elements can form hydrides, $\mathrm{AsH}_{3}$ and $\mathrm{PH}_{3}(30)$. The difference is that arsenates are much less stable than phosphates and as a consequence $\mathrm{AsH}_{3}$ will be formed even when $\mathrm{\Lambda l}_{2} \mathrm{O}_{3}$ is used as a support.

In contrast to carbon-supported Mo catalysts, alumina-supported Mo catalysts are not poisoned under our reaction conditions by the presence of phosphorus. Obviously, no phosphine is formed on the alumina-supported catalysts. Apparently, phosphate cannot be reduced, most probably because it is tightly bound to the alumina carrier. Evidence for this can be found in the literature. For instance, Gishti et al. (11) found, in studying the role of phosphate in oxidic $\mathrm{Mo} /(\mathrm{Al}+\mathrm{P})$ catalysts, that phosphate ions interact with the surface basic sites of the $\mathrm{Al}_{2} \mathrm{O}_{3}$ support. Haller et al. (31) found, in studying a high-temperature calcined $\mathrm{Ni}$ $\mathrm{Mo} /(\mathrm{Al}+\mathrm{P})$ catalyst with ${ }^{27} \mathrm{Al}$ NMR, that phosphorus inhibits the formation of $\mathrm{Al}_{2}\left(\mathrm{MoO}_{4}\right)_{3}$, because of the formation of $\mathrm{AlPO}_{4}$ species. The amount of phosphate ions that can interact with the surface sites of the alumina support is, however, probably limited.

When the phosphate content is too high, part of the phosphate might not be bound to the alumina carrier and, as a consequence, can be reduced to phosphine during sulfidation, resulting in a poisoning of the metal sulfides. Evidence for this can be found in the work of Muralidhar et al. (32), who studied the effect of different additives, among them $\left(\mathrm{NH}_{4}\right)_{2} \mathrm{HPO}_{4}$, on the catalytic function of a sulfided $\mathrm{Co}-\mathrm{Mo} / \mathrm{Al}$ catalyst. They found that $\left(\mathrm{NH}_{4}\right)_{2} \mathrm{HPO}_{4}$ present at 0.5 wt\% slightly promotes the thiophenes HDS activity measured at atmospheric pressure and $673 \mathrm{~K}$, whereas $\left(\mathrm{NH}_{4}\right)_{2} \mathrm{HPO}_{4}$ present at $5.0 \mathrm{wt} \%$ resulted in an $80 \%$ decrease in thiophene HDS activity. It is also reported (2) that a $\mathrm{Ni}-\mathrm{Mo} / \mathrm{Al}$ catalyst with a high phosphate content (larger than $12 \mathrm{wt} \%$ $\mathrm{H}_{3} \mathrm{PO}_{4}$ ) showed decreasing HDS and HDN activities.

It is clear that in the case of carbon as a support, phosphate is easily reduced to phosphine, due to the inert character of the carbon carrier. As a result, phosphorus poisoning is large even at low phosphate contents. In the case of alumina as a support, due to the strong phosphate-support interaction, reduction of phosphate is nil up to moderate phosphate contents and therefore poisoning is absent. In fact, due to this strong phosphate-alumina intcraction, phosphorus acts as a promoter, reportedly by preventing the formation of catalytically inactive metal aluminates, e.g., $\mathrm{Al}_{2}\left(\mathrm{MoO}_{4}\right)_{3}$ (3I), and by increasing the strength and heat stability of the alumina support (10, 11). Also, the dispersion is supposed to be 
improved when phosphoric acid is present in the impregnation solution $(1-3,6-9)$. However, if phosphate is present in excess, poisoning might take place. Thus, the amount of phosphoric acid used during catalyst preparation should not exceed the maximum phosphate binding capacity of the carrier material.

\section{CONCLUSIONS}

The thiophene HDS activity of carbonsupported molybdenum sulfide catalysts is strongly decreased by phosphorus, present as phosphate in the oxidic precursor catalyst. Alumina-supported Mo catalysts, on the other hand, are not poisoned by phosphorus at the same phosphorus-to-metal ratios as used for the carbon-supported catalysts.

XPS studies on the carbon-supported phosphorus-containing catalysts showed that the oxidic molybdenum phase can be easily converted to the sulfide form. XPS also showed that the dispersion of the active phase present in the sulfided catalyst is not significantly decreased in the presence of phosphorus.

It is suggested that the poisoning of the carbon-supported catalysts by phosphorus is related to phosphine $\left(\mathrm{PH}_{3}\right)$, which is formed by reduction of phosphate, probably during the presulfidation treatment. This phosphine might adsorb onto the anion vacancies of the metal sulfides and thus inhibit the absorption of thiophene onto these vacancies. As a consequence, the catalyst is deactivated.

The observation that phosphorus does not poison alumina-supported catalysts can be explained by the strong interaction of phosphate with the alumina support. Because of this strong interaction phosphate will not be reduced to phosphine.

\section{ACKNOWLEDGMENTS}

The authors thank Professor J. C. Duchet (University of Caen, France) for providing the CO chemisorption data and stimulating discussions, A. Heeres (University of Groningen, The Netherlands) for help in recording the XP spectra, and Professor P. B. Wells
(University of Hull, England) for helpful discussions on the effect of phosphate and phosphine.

\section{REFERENCES}

1. Haresnape, J. N., and Morris, J. E., British Patent 701,217 (1953).

2. Colgan, J. D., and Chonitz, N., U.S. Patent 3,287,280 (1966).

3. Michelson, G. A., U.S. Patents 3,749,663, $3,755,196,3,755,150,3,755,148$, and $3,749,664$ (1973).

4. Pine, L. A., U.S. Patent 3,904,550 (1975).

5. Eberly, P. E., Jr., U.S. Patent 4,003,828 (1977).

6. Chadwick, D., Aitchison, D. W., BadillaOhlbaum, R., and Josefsson, L., in "Preparation of Catalysts III"' (G. Poncelet, P. Grange, and P. A. Jacobs, Eds.), p. 323. Elsevier, Amsterdam, 1982.

7. Millman, W. S., U.S. Patent, 4,392,985 (1983).

8. Wilson, G., and Kayamote, M., U.S. Patent $4,388,222$ (1983).

9. Fitz, C. W., Jr., and Rase, H. F., Ind. Eng. Chem. Prod. Res. Dev. 22, 40 (1983).

10. Hopkins, P. D., and Meyers, B. L., Ind. Eng. Chem. Prod. Res. Dev. 22, 421 (1983).

11. Gishti, K., Iannibello, A., Marengo, S., Morelli, G., and Titarelli, P., Appl. Catal. 12, 381 (1984).

12. "Aqueous Solutions of Molybdenum Compounds for Catalytic Applications." Bulletin Cdb-16 of the Molybdenum Climax Co., CT, 1973.

13. Okamoto, Y., Gomi, I., Mori, Y., Imanaka, T., and Teranishi, S., React. Kinet. Catal. Lett. 22, 417 (1983).

14. Voorhies, J. D., U.S. Patent 4,082,652 (1978).

15. Duchet, J. C., Van Oers, E. M., de Beer, V. H. J., and Prins, R., J. Catal. 80, 386 (1983).

16. Vissers, J. P. R., Lensing, T. J., de Beer, V. H. J., and Prins, R., in "Proceedings of the 16th Biennial Conference on Carbon, San Diego, 1983," p. 607. 1983.

17. Norit Testing Methods, Norit N.V., Amersfoort.

18. Van Sint Fiet, T. H. M., Ph.D. thesis, Eindhoven, 1973.

19. Konings, A. J. A, van Doorn, A. M., Koningsberger, D. C., de Beer, V. H. J., Farragher, A. L., and Schuit, G. C. A., J. Catal. 54, 1 (1978).

20. Kerkhof, F. P. J. M., and Moulijn, J. A., J. Phys. Chem. 83, 1612 (1979).

21. Penn, D. R., J. Electron Spectrosc. 9, 29 (1976).

22. Scofield, J. H., J. Electron Spectrosc. 8, 129 (1976).

23. Bachelier, J., Duchet, J. C., and Cornet, D., Bull. Soc. Chim. Belg. 90, 1301 (1981).

24. Terem, H. N., and Akalan, S., Compt. Rend. 228, 1437 (1949).

25. Balandin, A. A., Turova-Polyak, M. B., Levi, G. I., and Kheifits, L. A., Izv. Akad. Nauk SSSR Otd. Khim. Nauk, 1499 (1959). 
26. Bachelier, J., Duchet, J. C., and Cornet, D., J. Catal. 87, 283 (1984).

27. Bachelier, J., Tilliette, M. J., Cornac, M., Duchet, J. C., Lavalley, J. C., and Cornet, D., Bull. Soc. Chim. Belg. 93, 743 (1984).

28. Wagner, C. D., Riggs, W. M., Davis, L. E., Moulder, J. F., and Muilenberg, G. E., in "Handbook of X-Ray Photoelectron Spectroscopy." Perkin-Elmer Corp., 1979.

29. Merryfield, R. N., Gardner, L. E., and Parks, G.
D., "Catalyst Characterization Science" (M. L. Deving and J. L. Gland, Eds.), ACS Symp. Series 288. ACS, Washington, DC, 1985.

30. Cotton, F. A., and Wilkinson, G., in "Advanced Inorganic Chemistry," p. 373. Wiley, New York, 1972.

31. Haller, G., McMillan, B., and Brinen, J., J. Catal. 97, 243 (1986).

32. Muralidhar, G., Massoth, F. E., and Shabtai, J., J. Catal. 85, 44 (1984). 